\title{
Specificity and Application of the Lantibiotic Protease NisP
}

\author{
Manuel Montalbán-López ${ }^{\dagger \neq}$, Jingjing Deng ${ }^{\ddagger}$, Auke J. van Heel and Oscar P. Kuipers* \\ Department Molecular Genetics, University of Groningen, Groningen, Netherlands
}

Lantibiotics are ribosomally produced and posttranslationally modified peptides containing several lanthionine residues. They exhibit substantial antimicrobial activity against Gram-positive bacteria, including relevant pathogens. The production of the model lantibiotic nisin minimally requires the expression of the modification and export machinery. The last step during nisin maturation is the cleavage of the leader peptide.

OPEN ACCESS

Edited by:

Peter Neubauer,

Technische Universität Berlin,

Germany

Reviewed by:

Michael Gänzle,

University of Alberta, Canada

Osmar Nascimento Silva,

Universidade Católica Dom Bosco,

Brazil

*Correspondence:

Oscar P. Kuipers

o.p.kuipers@rug.nl

${ }^{\dagger}$ Present Address:

Manuel Montalbán-López, Department of Microbiology, Faculty of Sciences, University of Granada, Granada, Spain

${ }^{\ddagger}$ These authors have contributed equally to this work.

Specialty section:

This article was submitted to Microbiotechnology, Ecotoxicology and Bioremediation,

a section of the journal

Frontiers in Microbiology

Received: 09 November 2017

Accepted: 24 January 2018

Published: 09 February 2018

Citation:

Montalbán-López M, Deng J, van Heel AJ and Kuipers OP (2018) Specificity and Application of the

Lantibiotic Protease NisP.

Front. Microbiol. 9:160.

doi: 10.3389/fmicb.2018.00160
This liberates the active compound and is catalyzed by the cell wall-anchored protease NisP. Here, we report the production and purification of a soluble variant of NisP. This has enabled us to study its specificity and test its suitability for biotechnological applications. The ability of soluble NisP to cleave leaders from various substrates was tested with two sets of nisin variants. The first set was designed to investigate the influence of amino acid variations in the leader peptide or variations around the cleavage site. The second set was designed to study the influence of the lanthionine ring topology on the proteolytic efficiency. We show that the substrate promiscuity is higher than has previously been suggested. Our results demonstrate the importance of the arginine residue at the end of the leader peptide and the importance of lanthionine rings in the substrate for specific cleavage. Collectively, these data indicate that NisP is a suitable protease for the activation of diverse heterologously expressed lantibiotics, which is required to release active antimicrobial compounds.

Keywords: lantibiotic, nisin, bacteriocin, Lactococcus lactis, NisP, leader peptidase, subtilisin-like protease

\section{INTRODUCTION}

Lanthipeptides are posttranslationally modified peptides that contain dehydrated amino acids and (methyl)lanthionine residues (Knerr and van der Donk, 2012; Arnison et al., 2013). Lantibiotics are those lanthipeptides that have significant antimicrobial activity, namely lanthipeptide classes I and II. Some lantibiotics show activity against clinically relevant bacteria in a concentration range comparable to antibiotics in use. Moreover, they can target multidrug resistant bacteria (MotaMeira et al., 2000; Piper et al., 2009). The production of the model lantibiotic nisin (belonging to the class I lanthipeptides) by Lactococcus lactis requires the coordinated expression of 11 genes (Lubelski et al., 2008). Prenisin is produced as a linear prepeptide that undergoes dehydration and cyclization in a directional and alternating way (Lubelski et al., 2009) and is subsequently exported by a dedicated transporter (NisT). Outside the cell, the protease NisP cleaves off the leader peptide releasing mature nisin (Kuipers et al., 1993). In this process, the leader peptide of nisin serves as a recognition motif for the modification enzymes and the transporter and keeps the fully modified prenisin inactive until it is removed (Kuipers et al., 1993; van der Meer et al., 1993; Oman and van der Donk, 2010; Khusainov et al., 2011, 2013; Plat et al., 2011, 2013; Khusainov and Kuipers, 2012; Abts et al., 2013; Yang and van der Donk, 2013). 
The proteases involved in the maturation of lanthipeptides recognize different cleavage sites. The type I lanthipeptide proteases, generally referred to as LanP, are subtilisin-like serine proteases. They can be secreted to the extracellular medium, like EpiP (Geissler et al., 1996), or remain in the cytoplasm, like PepP (Meyer et al., 1995), or be exported and bound to the cell wall, like NisP. In the maturation of subtilin, no specific protease has been found and the processing takes place outside the cell probably by diverse serine proteases (Corvey et al., 2003). The first lantibiotic protease with a resolved 3D structure, EpiP from Staphylococcus aureus, an analog of NisP, has been reported (Kuhn et al., 2014; Xu et al., 2014). On the other hand, in type II lanthipeptides, the protease domain is fused to the transporter and this protein cleaves behind a double glycine motif (Knerr and van der Donk, 2012). In type III lanthipeptides, the cleavage is not so specific and is mediated by a prolyl oligopeptidase (Völler et al., 2013).

The modification enzymes of the nisin biosynthesis gene cluster have been used to produce potent and stable variants of clinically relevant peptides, providing extensive information regarding the promiscuity of the modification machinery (NisBC) and the transporter (NisT) (Kuipers et al., 2004; Kluskens et al., 2005, 2009; Rink et al., 2005, 2007a,b; Moll et al., 2010; Bosma et al., 2011; van Heel et al., 2016). The production of modified prelantibiotics allows to obviate the requirement for immunity and can achieve higher yields, although it requires a later activation by cleavage of the leader peptide (Valsesia et al., 2007; Majchrzykiewicz et al., 2010; Montalbán-López et al., 2017). Moreover, NisRK expressed in diverse strains provides a widely used inducible protein expression system for Grampositive bacteria (De Ruyter et al., 1996; Eichenbaum et al., 1998; Mierau and Kleerebezem, 2005).

The promiscuity of NisBTC and the development of an efficient production system for the modification and export of modified peptides enabled the production of putative lantibiotics from diverse bacteria in L. lactis (Majchrzykiewicz et al., 2010; van Heel et al., 2016). Moreover, this production system can be extended with additional enzyme modules (i.e., additional modification enzymes found in lantibiotic gene clusters) (van Heel et al., 2013) or with non-canonical amino acids (Zhou et al., 2016; Baumann et al., 2017; Zambaldo et al., 2017) that increase the repertoire of unusual amino acids that can be incorporated in vivo in peptides. These findings highlight the large potential of using Synthetic Biology principles in the production of novel lanthipeptides (for a review see Montalbán-López et al., 2012, 2017 and references therein). The versatility of the NisBTC system allows for the production of a large number of putative prelantibiotics. Thus, a protease capable of releasing the active lantibiotic during growth of the producer strain is indispensable for using high-throughput screening systems on novel peptides. Additionally, the production of modified prelantibiotics can achieve higher yields because no immunity is required being the only drawback the necessity of a suitable leader peptidase (Valsesia et al., 2007). Therefore, we tested the suitability of diverse commercial proteases for the cleavage of the leader peptide of nisin after maturation in various growth conditions. We compared their activity with that of the lantibiotic protease
NisP, especially in view of the importance of the variable residues present behind the cleavage site, to establish the potential of NisP for various biotechnological applications.

The nisin protease, NisP, is produced and exported to the outside of the cell, where it is anchored to the peptidoglycan via a sortase-catalyzed coupling and performs its function, although a fraction of the protease escapes anchoring (van der Meer et al., 1993; Siezen et al., 1995; Xu et al., 2014). It contains a typical N-terminal secretion signal, a protease domain, a selfcleavage $\mathrm{C}$-terminal sequence and a sortase recognition sequence (Figure 1A). The maturation of NisP involves the release of the signal peptide and part of the prepeptide, likely by self-cleavage of the N-terminal sequence (van der Meer et al., 1993), as has been shown for an EpiP-analog (Kuhn et al., 2014). Although the role of NisP in the production of nisin is crucial, little is known about the specificity of the protease or the recognition sites present in prenisin that allow for the binding and cleavage of the leader peptide, although recently the influence of lanthionine rings on processing specificity has been reported (Lagedroste et al., 2017). Moreover, the fact that NisP is attached to the cell wall has prevented a detailed study of the specificity of NisP. Here, we present a systematic study of an engineered soluble variant of the lantibiotic protease NisP. This work will greatly facilitate the efficient production and activation of a wide variety of active lantibiotics with a cost-effectively produced protease.

\section{MATERIALS AND METHODS}

\section{Bacterial Strains and Growth Conditions}

The bacterial strains and vectors used in this work are listed in Table 1. Lactococcal strains were grown in M17 (Oxoid), supplemented with $0.5 \%$ glucose $(\mathrm{GM}-17)$ at $30^{\circ} \mathrm{C}$ for genetic manipulation or in the same conditions, but in MEM for peptide production (Rink et al., 2005). Escherichia coli and Micrococcus flavus strains were grown in $\mathrm{LB}$ at $37^{\circ} \mathrm{C}$, while shaking at 250 rpm. When appropriate, erythromycin and/or chloramphenicol (Sigma-Aldrich) were added at a final concentration of $5 \mu \mathrm{g} / \mathrm{ml}$. Kanamycin (Sigma-Aldrich) was used at a final concentration of $20 \mu \mathrm{g} / \mathrm{ml}$.

\section{Construction of Expression Vectors}

Cloning steps were performed following standard protocols (Sambrook et al., 2001). The preparation of competent L. lactis cells and transformation were carried out according to Holo and Nes (1995). Restriction endonucleases and ligase were used as recommended by the provider (Thermo Fisher Scientific).

For the cloning of nis $P$ variants, the gene was amplified from the genome of L. lactis NZ9700 using primers nisPbsphfwd and nisP8KXbarev or nisPbsphfwd and nisP8KSacIr for the addition of a 8-mer poly-lysine tag, nisPbsphfwd and nisP8HXbarev or nisPbsphfwd and nisP8HSacIr for the addition of a 8-mer poly-histidine tag, or nisPbsphfwd and solNisPcontrol for the production of an untagged soluble NisP (Supplementary Table 1). The amplification was performed using Phusion Polymerase (Thermo Fisher Scientific) following the provider's instructions. After amplification, the DNA was purified using the PCR 


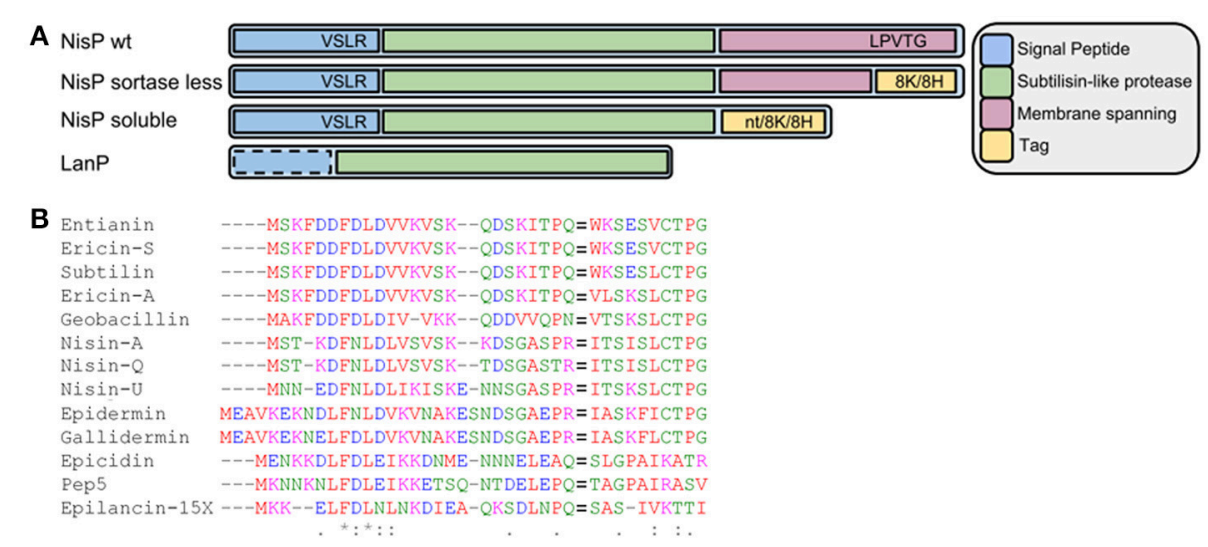

FIGURE 1 | (A) Schematic view of wild-type NisP, NisP mutants generated in this work and other LanPs. 8H represents the 8-histidine tag, 8K represents the 8-lysine tag, and nt denotes no tag added. The dotted line around the signal peptide in LanP indicates that this part is not present in all LanP proteases. (B) Alignment of diverse type I lantibiotic peptides. The F(D/N)LD motif and the Pro-2 are highly conserved. The cleavage site is indicated with an equal to sign (=).

cleaning kit (Roche) and digested with $\mathrm{BspHI}$ and $\mathrm{XbaI}$ or $\mathrm{BspHI}$ and SacI and ligated in pNZ8048 digested with NcoI and either $X b a \mathrm{I}$ or SacI. Similarly, the fragment was inserted into pET28b digested with NcoI and either SpeI or SacI. The ligation mix was transformed into L. lactis NZ9000 or E. coli Rosetta Blue DE3. The nucleotide sequence of each gene was checked by sequencing with the primers listed in Supplementary Table 1.

For the construction of pNZE3nisA-CAAAA-ASPR, the nisin CAAAA coding gene (last 4 Cys replaced by Ala) was synthesized by GeneArt and cloned into pNZE3-empty (van Heel et al., 2013) as a BglII-HindIII fragment encoding the $\mathrm{P}_{\text {nis }}$ promoter and nisin-CAAAA. For the construction of pNZE3nisA-CyslessASPR, Nisin Cys-less was amplified from pNZE3-Cys-less (Khusainov and Kuipers, 2013) using the primers pNZE3Emf and C-lessH6-less, digested with BglII and HindIII, and cloned into pNZE3-empty cut with the same enzymes. pNZE3nisAC7A-VSLR was produced by round PCR of pNZnisA-E3 using the primers NisPC7A-rev and NisPC7A-fwd. pNZE3nisA-C7AASPR was produced by round PCR of pNZE3nisA-C7A-VSLR using the primers NisPC7A-rev and NisPC7A-ASPR-fwd The equivalent genes in which the end of the leader peptide was mutated from ASPR to VSLR were generated by round-PCR of each of the plasmids mentioned above with the primers nisVSLRfwd and nisVSLRrev.

The nisin variants with a mutation in the first two amino acids of the core peptide were produced by round PCR of pNZnisAE3 using phosphorylated $\mathrm{P}$-for as a forward primer in all cases and P-IK-Rev, P-KT-Rev, P-WT-Rev, P-DT-Rev or P-IV-Rev for Nisin A-T2K, Nisin A-I1K, Nisin A-I1W, Nisin A-I1D and Nisin A-T2V mutants, respectively.

\section{Gene Expression and Product Purification}

An overnight culture of L. lactis NZ9000 grown in GM17 with the desired plasmid(s) was diluted 50-times in preheated MEM and grown until an OD $600 \mathrm{~nm}$ of 0.4-0.6. At this moment, the culture was induced with $5 \mathrm{ng} / \mathrm{ml}$ of nisin (SigmaAldrich). Cells were harvested after $3 \mathrm{~h}$ of induction and the supernatants containing the protein of interest were further purified.

Trichloroacetic acid (TCA) precipitation was carried out according to Sambrook et al. (2001). The purification of nisin and its mutants in higher amounts was performed according to described protocols (Lubelski et al., 2009). When higher purity was required, the fractions collected were applied to a spherical C18 versaflash column (Supelco) previously equilibrated in $0.1 \%$ trifluoroacetic acid (TFA). The column was washed in three steps with 3 volumes of 33,66 , and $100 \%$ organic solvent (2:1 isopropanol:acetonitrile $0.1 \%$ TFA). After this step, the peptides were concentrated by freeze-drying.

For the purification of soluble truncated NisP, the producer cells were grown and induced at an OD $600 \mathrm{~nm}$ of $0.4-0.6$ with either $5 \mathrm{ng} / \mathrm{ml}$ nisin or $1 \mathrm{mM}$ IPTG depending on the producer strain being L. lactis NZ9000 or E. coli Rosetta Blue $\mathrm{DE} 3$, respectively. The cells were separated after $3 \mathrm{~h}$ induction by centrifugation at $6,000 \mathrm{rpm}$ for $10 \mathrm{~min}$ at $4^{\circ} \mathrm{C}$. The his-tagged variant NisP-8H was purified by affinity chromatography using a Ni-NTA fast flow resin (Qiagen). Briefly, the cell-free supernatant of L. lactis strains or the cell-lysate of E. coli strains was passed through a column previously equilibrated with binding buffer (20 mM phosphate buffer $0.5 \mathrm{M} \mathrm{NaCl} \mathrm{pH} \mathrm{8.0).} \mathrm{The} \mathrm{column}$ was washed with $50 \mathrm{mM}$ phosphate buffer $0.5 \mathrm{M} \mathrm{NaCl} 20 \mathrm{mM}$ imidazole $\mathrm{pH}$ 8.0. NisP-8H was eluted from the column using $50 \mathrm{mM}$ phosphate buffer $0.5 \mathrm{M} \mathrm{NaCl} 250 \mathrm{mM}$ imidazole. NisP-8K was purified by cationic exchange chromatography using a Fastflow SP-sepharose (GE Healthcare). The column was equilibrated with 5 column volumes of $20 \mathrm{mM}$ phosphate buffer $\mathrm{pH}$ 6.5. The $\mathrm{pH}$ of the supernatant was adjusted to $\mathrm{pH} 6.5$ and then passed through the column. After washing with 5 column volumes of $20 \mathrm{mM}$ phosphate $\mathrm{pH} 6.50 .5 \mathrm{M} \mathrm{NaCl}$, the attached protein was eluted with $20 \mathrm{mM}$ phosphate $\mathrm{pH} 6.51 .5 \mathrm{M} \mathrm{NaCl}$.

The presence of NisP and its variants in elution fractions was assessed by checking the ability to activate prenisin in antimicrobial assays and/or by SDS-PAGE according to Laemmli (1970). 
TABLE 1 | Strains and vectors used in this work.

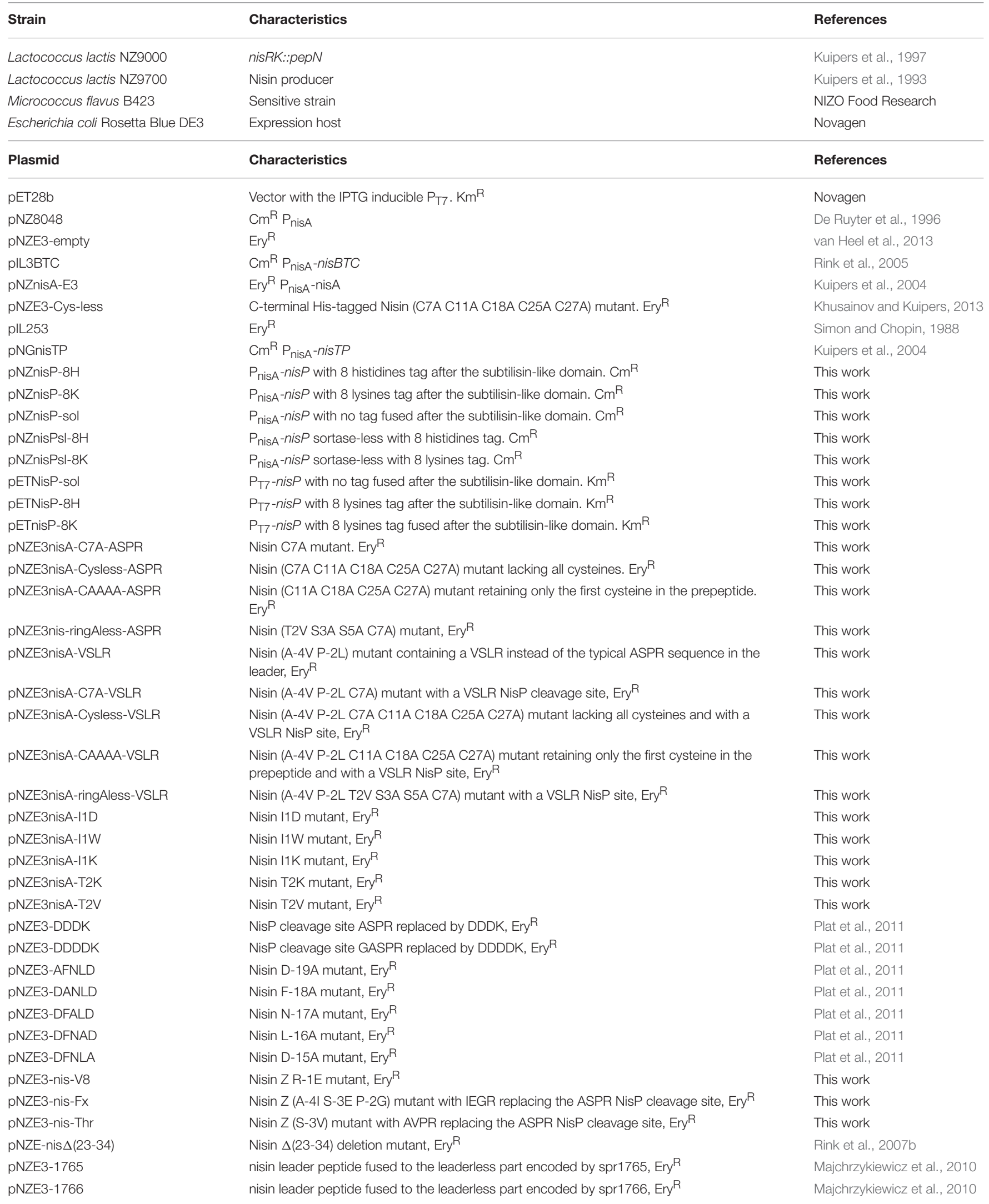

$\mathrm{Cm}^{R}$, chloramphenicol resistance; Ery ${ }^{R}$ erythromycin resistance. 


\section{Proteolysis of Nisin and Nisin Mutants Using NisP}

Lyophilized nisin or its mutants were solubilized using a $0.05 \%$ acetic acid solution. Different buffers were prepared: $1 \mathrm{M}$ HEPES, $1 \mathrm{M} \mathrm{NaCl}, 1 \mathrm{M}$ HEPES $50 \mathrm{mM} \mathrm{CaCl} 2,1 \mathrm{M}$ HEPES $50 \mathrm{mM} \mathrm{MgCl}$, $1 \mathrm{M}$ MES, $1 \mathrm{M}$ MES $50 \mathrm{mM} \mathrm{CaCl}_{2}$. In all cases, the $\mathrm{pH}$ was adjusted to 6.5 and mixed with each sample and then diluted 10 times. Additionally, $1 \mathrm{M}$ Tris $50 \mathrm{mM} \mathrm{CaCl}_{2} \mathrm{pH} 6.0$ was tested. The $\mathrm{pH}$ was measured after mixing and corrected if necessary.

Alternatively, supernatants containing nisin mutant peptides produced after induction were divided into two fractions; one in which the $\mathrm{pH}$ was adjusted to 6.0 and the other one where the $\mathrm{pH}$ was the actual fermentation $\mathrm{pH}$. They were incubated overnight at $37^{\circ} \mathrm{C}$ with or without His-tagged purified NisP at a ratio of 1000:1. After the incubation, the supernatants were precipitated using TCA and resuspended in $1 / 20$ volume $0.05 \%$ acetic acid. For the mutants that were produced in lower amounts, larger volumes were induced and the peptides were purified by cationic exchange chromatography as described before and separated by reverse phase chromatography using a Jupiter $4 \mu \mathrm{m}$ Proteo 90 $\AA 250 \times 4.6 \mathrm{~mm} \mathrm{C12}$ analytical column (Phenomenex). The column was equilibrated in $20 \%$ organic solvent (acetonitrile $0.1 \%$ TFA) before the sample injection. It was washed for $5 \mathrm{~min}$ before applying a linear gradient from 20 to $50 \%$ organic solvent in $20 \mathrm{~min}$. $1 \mathrm{\mu l}$ of each collected peak was used for massspectrometry determination.

\section{MALDI-ToF Mass Spectrometry Characterization}

Mass spectrometry analysis of the samples was performed by matrix-assisted laser desorption/ionization (MALDI) time-offlight (ToF) in an ABI Voyager DE Pro (Applied Biosystems) operating in linear mode as previously described using external calibration (van Heel et al., 2013). Briefly, $1 \mu$ l sample was spotted, dried and washed with $5 \mu \mathrm{L}$ Milli-Q water, on the target. Next, $1 \mu \mathrm{l}$ of $\alpha$-cyano-4-hydroxycinnamic acid $5 \mathrm{mg} / \mathrm{ml}$ (Sigma-Aldrich) was spotted on the sample.

\section{Activity Test}

Activity tests were performed by well-diffusion assay as indicated by van Heel et al. (2013). L. lactis NZ9000 transformed with the appropriate plasmids or Micrococcus flavus were used as sensor strains as specified in each figure. The cleavage of nisin by NisP after SDS-PAGE was monitored washing the gel according to Bhunia et al. (1987) and covering with an overlay of GM17 soft agar inoculated with NZ9000 (pIL3BTC pNZnisAE3) induced with $1 \mathrm{ng} / \mathrm{ml}$ nisin. The overlay was incubated for $16 \mathrm{~h}$, after which the presence of inhibition zones was evaluated.

\section{Enzyme Kinetic Assays}

In order to investigate the substrate specificity and kinetic parameters of NisP, a set of mutants of P4-P1 was created. We used wild-type prenisin (ASPR), nis-Peng (VSLR), nisThrombin (AVPR), and nis-Factor Xa (IEGR) as substrates. The concentration of NisP was determined by the BCA assay with bovine serum albumin as standard. The conditions of cleavage reaction were optimized with $100 \mathrm{mM}$ Tris buffer containing $5 \mathrm{mM} \mathrm{CaCl}_{2}$ (pH 6.0). The reaction was stopped at the indicated times adding TFA to a final concentration of $1 \%$. The reaction was performed in $100 \mu \mathrm{l}$ with $6.5 \mathrm{ng} / \mathrm{ml} \mathrm{NisP}$ at $37^{\circ} \mathrm{C}$. $1 \%$ TFA was added to terminate the reaction at 5 different time points $(5,15$, 30,45 , and $60 \mathrm{~min}$ ). All the samples were analyzed by analytical RP-HPLC as indicated before (Mu et al., 2015) and measuring the absorbance at $205 \mathrm{~nm}$. For each substrate concentration, the initial velocity was calculated on the basis of the peak area of released nisin vs. time. The kinetic parameters were determined by fitting the calculated enzyme activities at different substrate concentrations (ranging from 1 to $25 \mu \mathrm{M}$ ) to a linear regression curve on Lineweaver-Burk double reciprocal plot (Lineweaver and Burk, 1934).

\section{RESULTS}

\section{Cloning and Expression of a Soluble NisP Variant}

The fact that NisP is a cell wall anchored protease has hindered a thorough characterization and assessment of its biotechnological properties. In a first attempt to produce soluble NisP, we designed primers that hybridize partially to the sequence of NisP immediately upstream of the sortase recognition sequence in the C-terminus of NisP (LPVTG). We designed the primers nisP8KXbarev and NisP8HXbarev, which add a tail of 8-Lys or 8 -His residues, respectively. These tags facilitate the purification of the protease and can also serve for the immobilization on different materials for high-throughput applications.

The supernatants of the strains NZ9000 (pNZnisPsl-8H) and NZ9000 (pNZnisPsl-8K) were tested for the presence of protease activity after $3 \mathrm{~h}$ of induction with nisin. In each case, $5 \mu \mathrm{l}$ of the supernatant was mixed with $50 \mu \mathrm{l}$ of prenisin obtained by TCA precipitation of induced NZ9000 (pIL3BTC pNZnisA-E3). Positive controls using trypsin or the supernatant of induced NZ9000 (pNGnisTP) and a negative control containing only prenisin were used. The presence of an appropriate protease in the mix will release active nisin, thus we can monitor the activity of NisP by measuring the antimicrobial activity against the sensitive strain Micrococcus flavus. We could observe antimicrobial activity only in the positive controls, thus indicating that the variant NisP protease, if produced, is not active (data not shown).

In a second approach, we attempted to reduce the size of NisP, while keeping the active subtilisin-like domain intact. An alignment comparing different LanP proteases shows that NisP has a hydrophobic helix after the protease domain which is not present in other intracellular proteases (Velásquez et al., 2011). Thus, we decided to express a NisP variant that lacks the sortase recognition sequence and this motif. Similarly, we amplified the gene adding a C-terminal tag of either 8 histidines, or 8 lysines or no tag. We repeated the activity test with the supernatants of induced L. lactis NZ9000 (pNZnisP-sol), NZ9000 (pNZnisP-8H) and NZ9000 (pNZnisP-8K) (Figure 2A). In this case we were able to detect antimicrobial activity for all the 
A

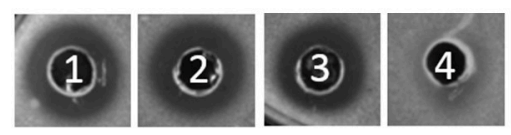

B

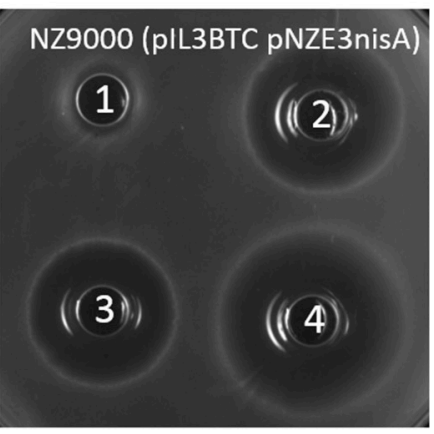

C

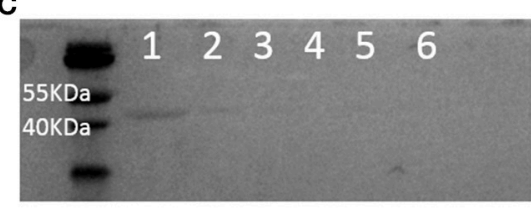

D

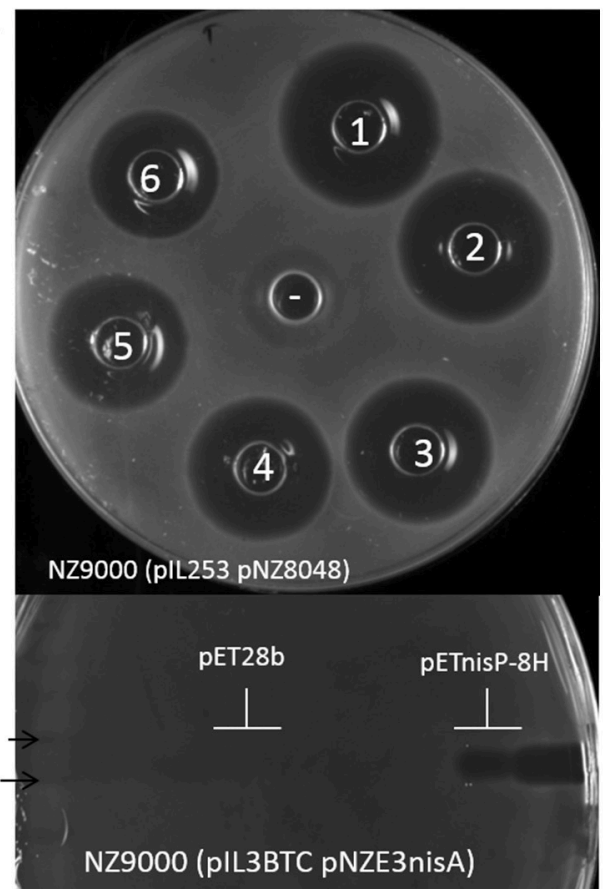

FIGURE 2 | Activity of engineered NisP variants. (A) Activation of prenisin with supernatants of induced L. lactis NZ9000 transformed with pNZnisP-sol (1), pNZnisP-8H (2), pNZnisP-8K (3), or pNGnisTP (4), using M. flavus as an indicator strain. (B) Activity of NisP heterologously produced in E. coli Rosetta Blue DE3 using the prenisin producing strain L. lactis NZ9000 (pNZnisA-E3 plL3BTC) both as producer and as sensitive strain. $20 \mu$ l of cell lysate of E. coli (pET28b) (1), E. coli (pETNisP-sol) (2) or E. coli (pETNisP-8H) (3) were added to the wells. $1 \mu$ of NisP-8H purified from L. lactis NZ9000 (pNZnisP-8H) was used as a positive control (4). (C) SDS-PAGE of NisP-8H purified by affinity chromatography from L. lactis NZ9000 (pNZnisP-8H). Wells 1-6 contain $15 \mu \mathrm{l}$ of each $2 \mathrm{ml}$-fraction collected. (D) Activation of prenisin by NisP-8H purified from L. lactis NZ9000 (pNZnisP-8H) using L. lactis NZ9000 (pNZ8048 plL253) as a sensitive strain. Wells 1-6 correspond to a mix of $50 \mu \mathrm{l}$ of supernatants of induced L. lactis NZ9000 (pNZnisA-E3 plL3BTC) and $2 \mu$ l of purified NisP from the batch shown in (C). (E) Activity test of NisP-8H from E. coli Rosetta Blue DE3 (pETnisP-8H) after separation by SDS-PAGE. L. lactis NZ9000 (pNZnisA-E3 pIL3BTC) was used both as producer and as sensitive strain.

soluble truncated NisP variants, with or without a tag attached to the C-terminus of the protein. Additionally, the size of the inhibition halo measured is larger in the samples activated with the soluble protease present in the supernatants of these three engineered strains compared to the samples activated with the supernatant of L. lactis NZ9000 (pNGnisTP), which produces as a major product wild-type cell-anchored NisP. This indicates that the amount of truncated NisP in the supernatants is higher than the amount of wild-type NisP exposed by the cells. These results demonstrate that the engineered NisP variants containing only the protease domain can be recovered from the supernatants. It also shows that C-terminally tagged NisP retains good activity.

The truncated NisP variants were also cloned in an E. coli expression vector, rendering pET28-NisP-8H, pET28-NisP-8K, and pET28-NisP-sol. The cell pellet obtained after induction of E. coli Rosetta Blue DE3 transformed with these vectors was disrupted using glass beads and used in an antimicrobial assay to activate prenisin. It was possible to activate prenisin using this fraction, showing the ability of $E$. coli to produce active truncated NisP (Figure 2B). Moreover, the supernatants of the induced cultures were also able to activate prenisin whereas the control did not.

\section{Purification of NisP and Optimization of Cleavage Conditions}

The strains L. lactis NZ9000 (pNZnisP-8H) and NZ9000 (pNZnisP-8K) were induced and the production of protease was monitored by SDS-PAGE of the diverse fractions collected during the purification by either affinity chromatography or cation exchange chromatography, respectively. We could clearly detect a highly pure band of approximately $42 \mathrm{kDa}$, which is the expected size after removal of the signal peptide during production (Figure 2C) with an average yield of $1 \mathrm{mg} / \mathrm{L}$. The protease activity of each fraction was monitored by activation of prenisin (Figure 2D). Surprisingly, even in fractions for which the sensitivity of Coomassie blue staining was too low to detect the protease, activity could still be detected. Similarly, after induction of E. coli Rosetta Blue DE3 (pET28-NisP-8H) or (pETNisP-8K) a protein of approximately $42 \mathrm{kDa}$ was detected in the supernatants by SDS-PAGE. The gel was covered with a prenisin producing $L$. lactis strain demonstrating that this protein could activate prenisin and create an inhibition zone (Figure 2E).

The activity of NisP on wild-type prenisin was tested in different buffers based on Tris, HEPES or MES with or without calcium and magnesium and monitored by HPLC. We conducted the experiments in duplicate at 30 and $37^{\circ} \mathrm{C}$. We found that the 
cleavage in $100 \mathrm{mM}$ tris buffer $\mathrm{pH} 6.0$ supplemented with $5 \mathrm{mM}$ $\mathrm{CaCl}_{2}$ at $37^{\circ} \mathrm{C}$ was the optimal buffer for the reaction, although the protease was still reasonably active in the other conditions (data not shown).

\section{Prenisin Specific Cleavage Using Specific Proteases in Culture Conditions}

To further compare the versatility of NisP in culture conditions with various proteases frequently used in biotechnology, we mutated the last four amino acids in the leader peptide (P4-P1) of nisin (i.e., ASPR) to insert a factor Xa (IEGR) or a thrombin (AVPR) cleavage site. We also mutated the arginine in position P1 of the leader peptide into glutamic acid, creating a cleavage site for the endoprotease Glu-C. Additionally, the proposed selfcleavage sequence of NisP (VSLR) (Figure 1, van der Meer et al., 1993) was used to replace the ASPR sequence at the end of the nisin leader peptide. The supernatants of the prenisin producer strains containing these mutations were placed in a well on the agar plate and the specific proteases were added. The cleavage was evaluated by activity against NZ9000 (pIL253 pNZ8048), which is resistant to the erythromycin and chloramphenicol present in the supernatants of the substrate producer strains but sensitive to nisin. In these conditions, except for Factor Xa, all the proteases tested (thrombin, NisP and endoprotease Glu-C) were active (Figure 3).

\section{Specificity of NisP}

We designed a set of nisin mutants to investigate the specificity of NisP (Figure 4). For all these mutants, supernatants were collected after induction and divided into three fractions. NisP was added to two of these fractions, one maintaining the $\mathrm{pH}$ of the culture (4.5-5.0) and the other fraction was adjusted to $\mathrm{pH}$ 6.0. The third fraction was used as an untreated control. After cleavage, the masses of the peptides were monitored by MALDI-TOF (Table 2).

\section{Lanthionine Ring-Impaired Nisin Mutants}

We designed variants of nisin containing only the first ring (nisin-CAAAA), lacking the first ring (nisin-C7A) and lacking all the rings (nisin-Cys-less). In order to discard an abnormal ring formation between Cys11 and an N-terminal dehydrated residue other than Thr8 in the mutant nisin-C7A, we designed the mutant nisin-ringA-less, where the first dehydratable residue is Thr8 and therefore we abolish the possibility of any aberrant ring formation. Additionally, we mutated the residues P4 to P1 in the leader peptide of nisin to create a VSLR cleavage sequence in nisin, nisin-CAAAA, nisin-C7A, nisin-ringA-less and nisinCys-less. We observed that wild-type nisin was fully cleaved, independently of the cleavage sequence at the end of the leader peptide being ASPR or VSLR. In the other cases, although most of the cleavage took place in the right position, we were able to detect masses corresponding to aberrant cleavage by NisP (Table 2).

The mutant lacking all the cysteines (nisin-Cys-less) was produced in a very low amount, irrespectively of the cleavage site present. After the cleavage of nisin-Cys-less, diverse peaks with a mass corresponding to the cleaved and dehydrated peptide

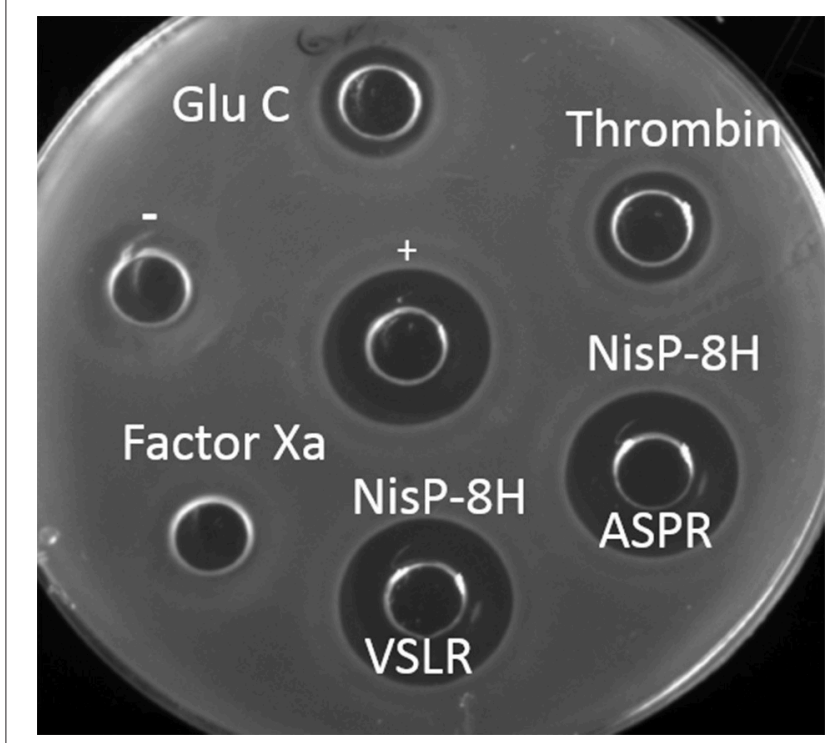

FIGURE 3 | Activity of the proteases in crude supernatants. Antimicrobial assay against L. lactis NZ9000 (plL253 pNZ8048) using different proteases. Each protease $(1 \mu \mathrm{l})$ was mixed with supernatant containing $50 \mu \mathrm{l}$ of its corresponding prenisin variant. Activity observed results from protease activity on the substrate releasing active nisin. + indicates a positive control of $50 \mu \mathrm{l}$ nisin $10 \mathrm{ng} / \mu \mathrm{l}$. - indicates a negative control of untreated prenisin. Supernatants of induced L. lactis NZ9000 (plL3BTC pNZE3nis-V8) (Glu-C), NZ9000 (plL3BTC pNZE3nis-Thr) (Thrombin), NZ9000 (plL3BTC pNZE3nisA-ASPR) (NisP-8H ASPR), NZ9000 (plL3BTC pNZE3nisA-VSLR) (NisP-8H VSLR), NZ9000 (plL3BTC pNZE3nis-Fx) (Factor Xa) were mixed with $1 \mu \mathrm{l}$ of the specific protease.

were detected with a small fraction of incorrectly processed nisin containing additional residues from the leader peptide (Table 2). Similarly, in the mutants nisin-CAAAA, nisin-C7A and nisinringA-less, small peaks corresponding to peptides cleaved at abnormal P1 or P2 positions in the leader peptide were also observed (Table 2). In the mutants nisin-C7A and nisin-ringAless, a small fraction of nisin lacking the first amino acid(s) was also identified, suggesting cleavage at alternative positions.

\section{Cleavage Site Mutants}

Various amino acid residues were replaced at the $\mathrm{N}$-terminus of the nisin core peptide (positions $\mathrm{P}^{\prime}$ and $\mathrm{P} 2^{\prime}$ ) to investigate the influence of these residues on the cleavage by NisP. We engineered positive and negative charges (nisin $\mathrm{I} 1 \mathrm{~K}$, nisin $\mathrm{T} 2 \mathrm{~K}$, and nisin I1D), a bulky amino acid (nisin I1W) and a hydrophobic amino acid in the second position of nisin core peptide replacing the dehydrobutyrine residue (nisin T2V) (Table 2). In all $\mathrm{P}^{\prime}$ and $\mathrm{P} 2^{\prime}$ mutants, we could detect inhibition of growth of sensor bacteria after activation with NisP. This indicates that these positions can tolerate a large variety of amino acids of very different nature and can still be cut by the specific protease and retain antimicrobial activity. It was possible to detect a small fraction of uncleaved peptide after the incubation of the mutant nisin I1D with the protease, which indicates reduced cleavage efficiency. The mutant nisin I1K rendered a 


\begin{tabular}{|c|c|c|}
\hline \multicolumn{3}{|c|}{ Single amino acid replacements } \\
\hline & $\mathrm{V} \mathrm{E} \mathrm{KK}$ & $\mathbf{A}^{\star}$ \\
\hline Nisin* & \multicolumn{2}{|c|}{ MSTKDFNLDLVSVSKKDSGASPR-ITSISLCTTPGCKTGALMGCNMMKTATCHCSIHVSK } \\
\hline No ring $A^{*}$ & \multicolumn{2}{|c|}{ MSTKDFNLDLVSVSKKDSGASPR-IVAIALATPGCKTGALMGCNMKTATCHCS IHVSK } \\
\hline CAAAA* & \multicolumn{2}{|c|}{ MSTKDFNLDLVSVSKKDSGASPR-ITSISLCTPGAKTGALMGANMKTATAHAS IHVSK } \\
\hline C-less $^{*}$ & \multicolumn{2}{|c|}{ MSTKDFNLDLVSVSKKDSGASPR-ITSISLATPGAKTGALMGANMKTATAHAS IHVSK } \\
\hline DDDK & \multicolumn{2}{|c|}{ MSTKDFNLDLVSVSKKDSGDDDK-ITSISLCTPGCKTGALMGCNMKTATCHC S IHVSK } \\
\hline DDDDK & \multicolumn{2}{|c|}{ MSTKDFNLDLVSVSKKDSDDDDK-ITSISLCTPGCKTGALMGCNMKTATCHCS IHVSK } \\
\hline $\operatorname{Nisin} \Delta(23-34)$ & \multicolumn{2}{|c|}{ MSTKDFNLDLVSVSKKDSGASPR-ITSISLC TPGCKTGALMGCNMK-------- } \\
\hline Factor Xa & \multicolumn{2}{|c|}{ MSTKDFNLDLVSVSKKDSGIEGR-ITSISLC TPGCKTGALMGCNMKTATCHCS IHVSK } \\
\hline \multicolumn{3}{|c|}{ Multiple amino acid replacements } \\
\hline
\end{tabular}

$\square$ Normal cleavage

Partial cleavage $\square$ No cleavage

Partial incorrect cleavage

FIGURE 4 | Schematic representation of the cleavage of nisin mutants using NisP-8H. Single mutants are indicated with one letter above wild-type nisin sequence. Mutants with several amino acid replacements are depicted in bold letters under wild-type nisin sequence. Lanthione rings are represented as a continuous line connecting Ser or Thr to Cys. The * indicates that this result was also obtained using the same variant with a VSLR cleavages site instead of the wild type ASPR site.

small fraction of mature nisin with a mass difference consistent with the presence of Arg P1 in the mature peptide, indicating that the peptide is incorrectly cleaved behind ASP.

Additionally, we tested the efficiency of NisP to cleave other protease recognition sequences, namely Factor Xa, thrombin, endoprotease Glu-C, and enterokinase (DDDK and DDDDK sequences) (Table 2). NisP was able to cleave when a factor Xa or thrombin site was present. Surprisingly, the nisin mutant with a glutamic acid in the P1 position of the leader peptide (nisin V8) was cleaved, although only partially since uncut peptide was still visible after the experiment. The final amount of undigested peptide in case of the mutant nisin V8 was higher when the cleavage was performed at $\mathrm{pH}$ 6. The enterokinase sequences DDDK or DDDDK were not cleaved by NisP in the conditions tested. Noticeably, no unspecific cleavage in the core peptide of any of the tested mutants was observed in the conditions tested.

\section{Nisin Mutants in the (D)FNLD Box}

Previously reported single alanine replacements of the characteristic DFNLD motif of type I lantibiotics leader peptide were studied (Plat et al., 2011). In all cases, cleavage was taking place normally as shown by mass-spectrometry (Table 2) and antimicrobial assays (data not shown) were consistent with previous reports (Plat et al., 2011).

\section{Cleavage of Different Lantibiotic Substrates}

The substrate tolerance of soluble NisP was tested using a set of different lantibiotics. These were produced using the nisin modification machinery encoded in NZ9000 (pIL3BTC pNZE3mutant) and purified by cationic exchange chromatography. For this purpose, NZ9000 (pNZ-nisP-8H) was used as a sensor strain and tested using gallidermin (van Heel et al., 2013) and two lantibiotics detected in the genome of Streptococcus pneumoniae, PneA1 and PneA2 encoded in the genes spr1765 and spr1766, respectively, which were heterologously expressed in L. lactis fused to the nisin leader peptide (Majchrzykiewicz et al., 2010)
(Figure 5). We could clearly determine that in the absence of NisP, none of the prelantibiotics tested, not even prenisin, was active against the sensor strain (data not shown). The activity was restored when a strain producing soluble NisP was employed. We could also notice that the NisP producing strain showed increased sensitivity to nisin (data not shown).

\section{Kinetic Characterization of NisP}

The substrate specificity and kinetic parameters of engineered soluble NisP were investigated by using WT prenisin (ASPR), nisPeng (VSLR), nis-Thrombin (AVPR), and nis-Factor Xa (IEGR) as substrates. The $K_{m}$ and $V_{\max }$ values were determined using Lineweaver-Burk plots (Figure 6). When wild-type prenisin was used as substrate, NisP exhibited the highest catalytic efficiency $\left(K_{\text {cat }} / K_{m}=1.71 \times 10^{6} \mathrm{M}^{-1} \mathrm{~s}^{-1}\right)$ and affinity $\left(K_{m}=0.73 \mu \mathrm{M}\right)$. In comparison with wild-type prenisin (ASPR), Nis-Peng (VSLR) showed a slightly increased $K_{m}$ value, an identical $K_{\text {cat }}$ value and a comparable $K_{\text {cat }} / K_{m}$ values (Table 3). For nis-Thrombin (AVPR) and nis-Factor Xa (IEGR), the 5-6-fold decrease in $K_{c a t} / K_{m}$ was ascribed to a 10-11-fold increase in $K_{m}$ and 2-fold increase in $K_{c a t}$ compared with that of wild-type prenisin (Table 3). In summary, soluble NisP displayed the highest catalytic efficiency to wildtype prenisin (ASPR), followed by Nis-peng (VSLR). A 5-6fold decreased catalytic efficiency was observed when Thrombin (AVPR) and Factor Xa (IEGR) cleavage sites were engineered.

\section{DISCUSSION}

\section{Active Soluble NisP Can Be Produced and Purified}

During the production of nisin, the protease NisP is exported and anchored to the cell wall in a sortase-mediated manner. In previous attempts to characterize the specificity of NisP, the in vivo cleavage was based on the detection of the antimicrobial activity and the detection of mature lantibiotic compared to that of the prelantibiotic (van der Meer et al., 1994). The activity in vitro could be confirmed using membrane preparations of 
TABLE 2 | Cleavage of nisin mutants using NisP on crude supernatants of the producer strain directly after fermentation or with the pH adjusted to 6.0.

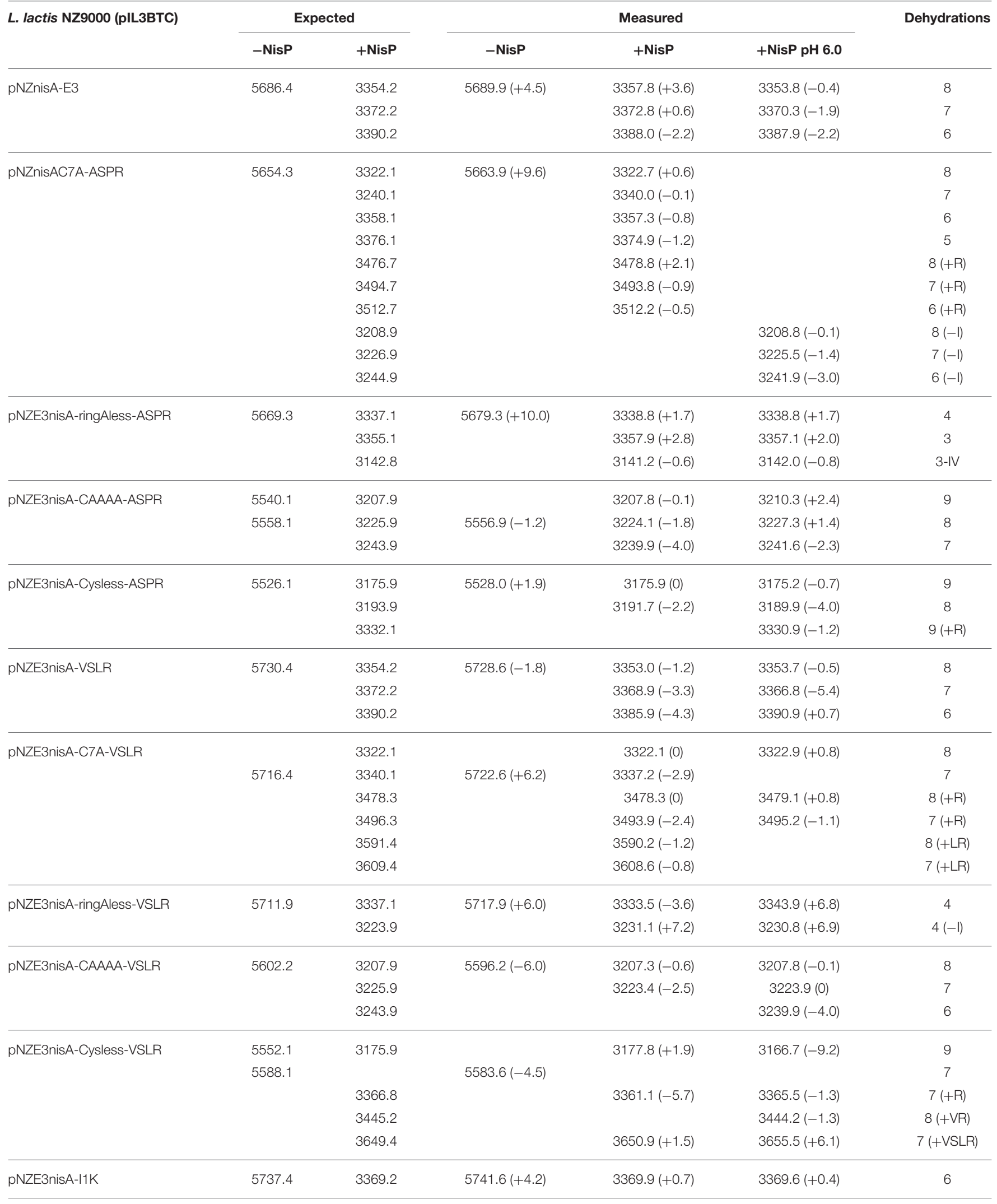


TABLE 2 | Continued

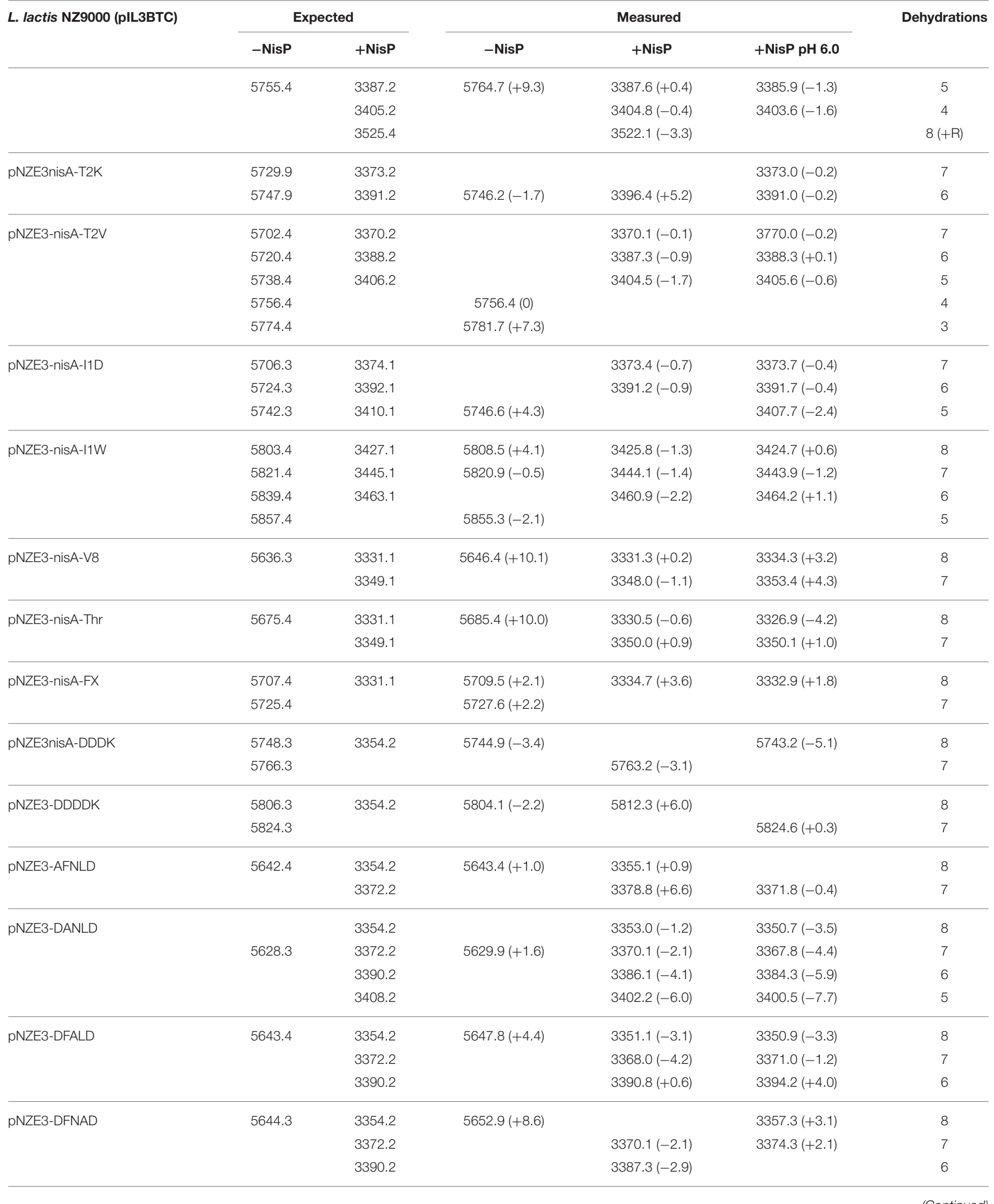


TABLE 2 | Continued

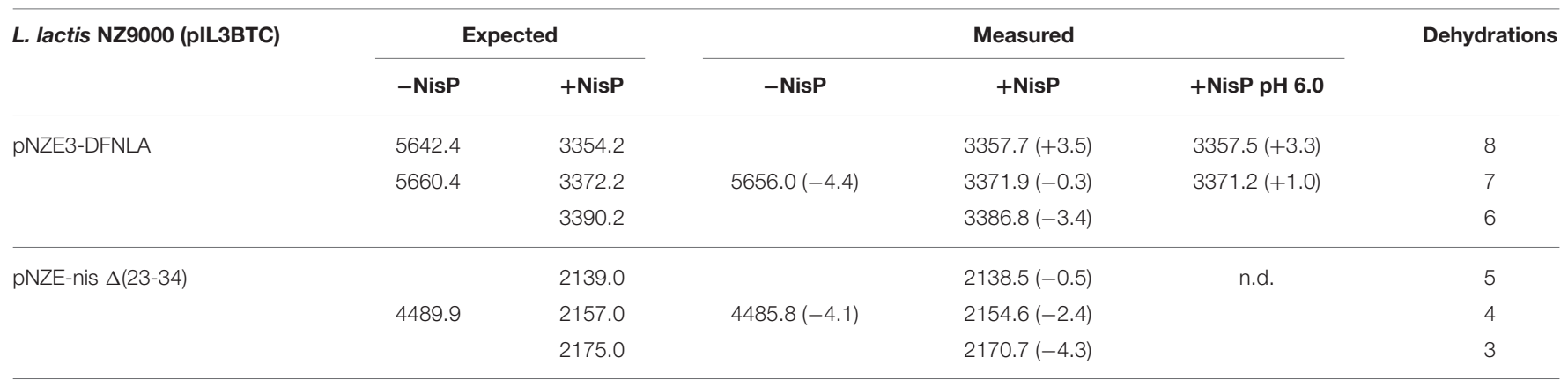

-, not addition of NisP; + addition of NisP; n.d., not determined.

The mass difference between the expected and the measured masses is displayed in brackets for each one of the possible dehydration statuses considered. In the case of misscleavage, the additional or lacking amino acids are displayed in brackets in the dehydration column together with the number of dehydroamino acids.

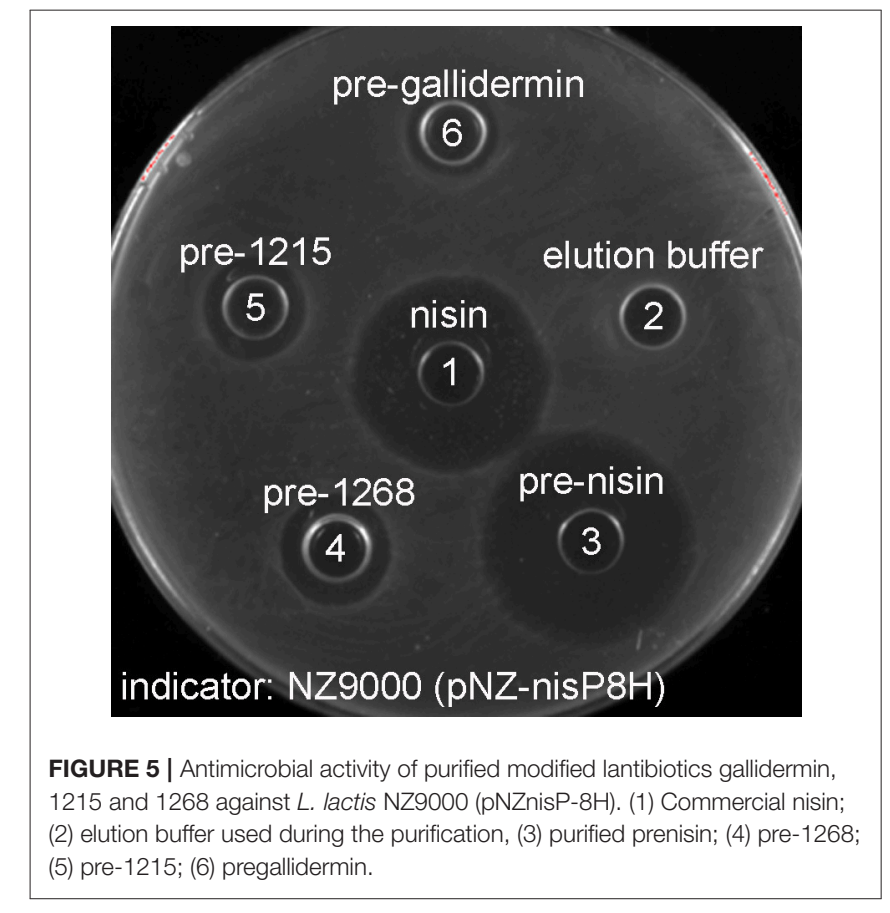

cells expressing NisP bound to the cell wall, which limited the assays. Therefore, we engineered a soluble NisP variant that could facilitate this task. Our initial hypothesis was that the removal of the sortase recognition sequence in NisP would abolish the binding, thus allowing for the purification of unbound protease in the supernatants (Figure 1). This approach failed to produce soluble NisP, maybe because NisP cannot fold properly or its solubility is reduced. Therefore, a second set of NisP mutants, trimmed at the C-terminus to remove the cell wall spanning helix, were designed. In this case, it was possible to produce detectable amounts of active NisP with the expected size in the supernatants. The activation of prenisin is unambiguously due to the action of this protease, since the strain with the empty vector was not able to activate prenisin. We also show that the purified protein could activate prenisin following SDS-PAGE electrophoresis, producing an inhibition halo around the band of the purified protease. These active NisP variants leave the subtilisin-like serine protease domain intact, and are more similar in size to other LanP-like proteases, which are naturally produced as soluble forms (EpiP, Geissler et al., 1996 or PepP, Meyer et al., 1995) or have been heterologously produced as soluble proteases (ElxP, Velásquez et al., 2011). Notably, E. coli was also able to produce mature NisP with the expected size in the supernatants (data not shown). This indicates that the secretion signal is correctly processed in E. coli and that the selfactivation of NisP can happen. In previous reported attempts to express the full length NisP in E. coli, no detection of the protease by Coomassie staining was possible. However, isotopelabeled methionine showed the production of a processed NisP with a size consistent with the removal of the signal sequence (van der Meer et al., 1993), as was observed in our study. This cell wall attached NisP could activate prenisin when cell extracts of induced E. coli were used (van der Meer et al., 1993). Importantly, the activity of NisP was not abolished by the addition of a C-terminal poly-histidine tag or a poly-lysine tag.

\section{NisP Tolerates Mutations at the $\mathrm{N}$-Terminus of Mature Nisin}

A homology modeling study on NisP based on the comparison with other proteases from the same family predicted an active site with a binding pocket that could fit 6 amino acids (P4, P3, P2, P1, $\mathrm{P}^{\prime}$, and $\mathrm{P} 2^{\prime}$ ) (Siezen et al., 1995). It predicts a strong interaction between the arginine in the position P1 with the protease mediated by electrostatic interactions with two aspartates in the enzyme that limits the amino acids in the positions $\mathrm{P}^{\prime}$ and $\mathrm{P} 2^{\prime}$ to be small hydrophobic amino acids (Siezen et al., 1995).

The presence of amino acids of diverse nature in the positions $\mathrm{P}^{\prime}$ and $\mathrm{P} 2^{\prime}$ of nisin shows that these residues can be mutated without altering the cleavage by NisP. It was anticipated that the binding of dehydrobutyrine in position $\mathrm{P} 2{ }^{\prime}$ was less important than the interaction of Ile in position $\mathrm{P} 1^{\prime}$ with a hydrophobic groove in NisP (Siezen et al., 1995). Some mutants like I1W were previously shown to be cut by NisP using only the antimicrobial activity as evidence (Kuipers et al., 1995). Here we show that it is fully processed under the experimental conditions used. We could observe that an additional positive charge in the 


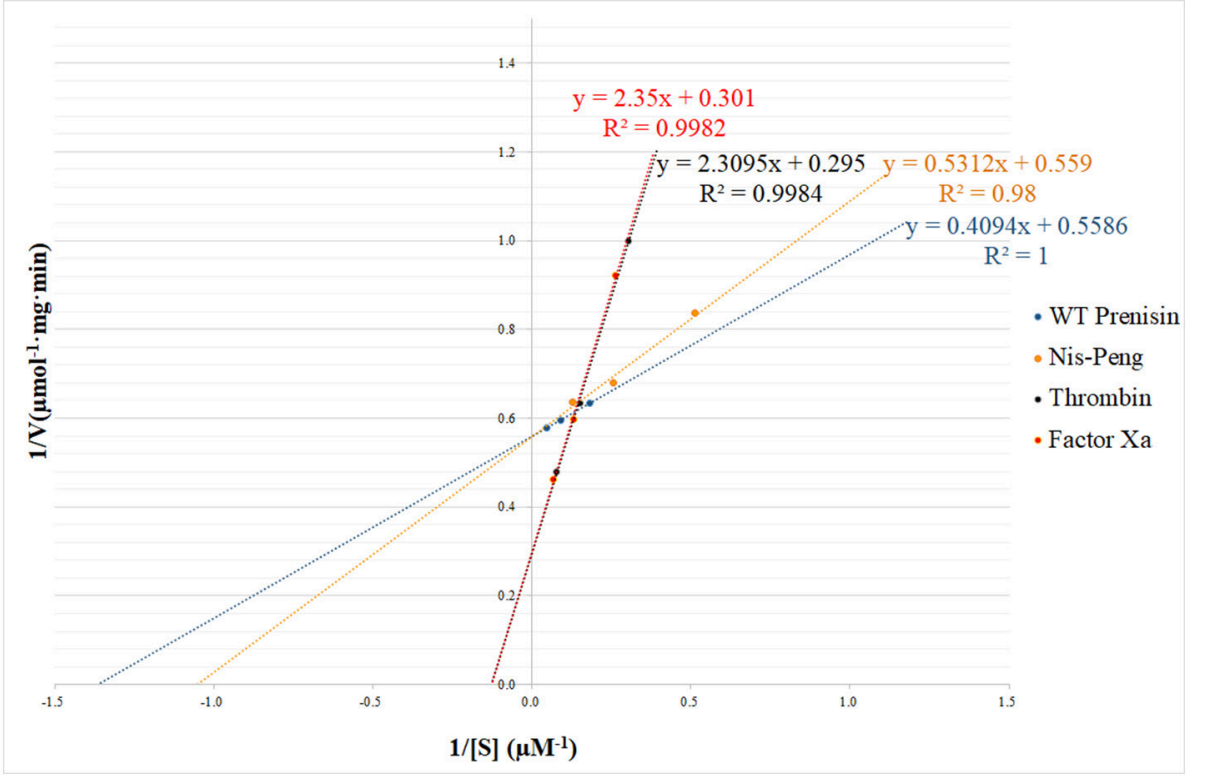

FIGURE 6 | NisP kinetic parameters determination using Lineweaver-Burk plot. The substrate concentrations ranged between 1 and $25 \mu \mathrm{M}$.

TABLE 3 | Kinetic characterization of the cleavage of several nisin leader peptide mutants.

\begin{tabular}{lcccc}
\hline Prenisin variants & $\mathbf{K}_{\mathbf{m}}(\boldsymbol{\mu} \mathbf{M})$ & $\begin{array}{c}\mathbf{V m a x} \\
(\boldsymbol{\mu} \mathbf{m o l} / \mathbf{m g} \mathbf{m i n})\end{array}$ & $\begin{array}{c}\mathbf{K}_{\mathbf{c a t}} \\
\left(\mathbf{s}^{-1}\right)\end{array}$ & $\begin{array}{c}\mathbf{K}_{\mathbf{c a t}} / \mathbf{K}_{\mathbf{m}} \\
\left(\mathbf{M}^{-1} \mathbf{s}^{-\mathbf{1}}\right)\end{array}$ \\
\hline WT Prenisin (ASPR) & $0.73 \pm 0.08$ & $1.79 \pm 0.10$ & $1.25 \pm 0.07$ & $1.71 \times 10^{6}$ \\
Nis-Peng (VSLR) & $0.95 \pm 0.08$ & $1.79 \pm 0.17$ & $1.25 \pm 0.11$ & $1.32 \times 10^{6}$ \\
Thombin (AVPR) & $7.83 \pm 0.27$ & $3.39 \pm 0.20$ & $2.37 \pm 0.14$ & $3.03 \times 10^{5}$ \\
Factor Xa (IEGR) & $7.81 \pm 0.01$ & $3.32 \pm 0.10$ & $2.33 \pm 0.07$ & $2.98 \times 10^{5}$ \\
\hline
\end{tabular}

Data indicate the mean value \pm standard deviation.

mutant I1K produced a small additional peak detected by massspectrometry consistent with a cleavage between positions $\mathrm{P} 2$ and $\mathrm{P} 1$, suggesting that the accumulation of positive charges favors a non-specific cleavage by NisP. Bulky or charged amino acids are well tolerated and the dehydrobutyrine in the second position, or a previously engineered dehydroalanine (Kuipers et al., 1995), are not the requirement for cleavage (Siezen et al., 1995).

\section{Lanthionine Rings in Nisin Are Not Essential for Cleavage by NisP}

Additional studies have suggested the requirement of lanthionine rings as a prerequisite for the substrate recognition (Kuipers et al., 2004). We engineered various mutants with altered lanthionine rings. NisP is supposed to cut in the VSLR+QP sequence in its N-terminus (van der Meer et al., 1993) and VSVR+S at the C-terminus (Xu et al., 2014), which lack lanthionine rings. Therefore, we hypothesize that a higher tolerance could be expected for mutants containing the engineered VSLR site in the leader peptide. Thus, we engineered in all the mutants with modified lanthionine ring topology the self-activation site proposed for NisP, the VSLR cleavage sequence. In previous work, a nisin mutant (A-4V,P-2L,I1Q,T2P, positions P4, P2, $\mathrm{P}^{\prime}$ and $\mathrm{P}^{\prime}$ according to Schechter-Berger nomenclature), containing the whole self-cleavage site of NisP was previously reported (van der Meer et al., 1993; Plat et al., 2011). We show here that VSLR+IT is also cleaved by NisP. The cleavage pattern observed in the mutants with different number of rings shows that the presence of lanthionine is not essential for the cleavage, since nisin Cys-less seems to be cleaved and so is nisin CAAAA. A similar situation was observed with the cleavage in vitro of unmodified pre-epilancin 15X and unmodified pre-epidermin with the specific proteases ElxP and EpiP, respectively (Geissler et al., 1996; Velásquez et al., 2011). This is in disagreement with previous work using whole cells expressing cell-attached NisP that suggests the requirement of lanthionine rings for the cleavage reaction (Kuipers et al., 2004). This discordance can be due to the amount of NisP expressed at the cell surface which could be too small compared to the addition of purified NisP, the additional replacements in nisin (S-6P, P-2L, positions P6 and $\mathrm{P} 2$, respectively) and/or the shorter incubation time used. It has been already shown that the binding affinity can be much higher for the fully modified prelantibiotic than for the unmodified one (Geissler et al., 1996; Lagedroste et al., 2017). Our results also indicate that although the lanthionine rings are not essential for the cleavage, they might favor the correct interaction with the protease and positioning of the substrate in the active site since small amounts of prenisin with either additional residues of the leader peptide or lacking some amino acids of the core peptide were visible, indicating occasional misprocessing. NisP production involves self-activation after the N-terminal signal peptide and cleavage at the C-terminus for optimal 
nisin production. Thus the promiscuity demonstrated in this study is also related to NisP expression itself (which recognizes different (auto-)processing sites). This can be exploited for specific peptide cleavage at various slightly different sites, when producing variant lantibiotics behind the nisin leader peptide (Supplementary Figure 1).

\section{NisP Cleaves in All Tested Protease Sites, Except in the Two Enterokinase Sites}

As mentioned before, the active site of NisP interacts with the last 4 residues of the leader peptide (Siezen et al., 1995). We modified these last positions in the leader peptide of nisin generating a set of diverse protease substrates. In such a way, we could investigate the specificity of NisP and simultaneously compare NisP with other proteases for the cleavage of the leader peptide in molecules modified using nisin biosynthesis machinery (vide infra).

The diverse protease sites engineered in the leader peptide prove that, except for the two enterokinase sites, all the other cleavage sequences tested could be cleaved by NisP, albeit with different efficiencies. Our $\mathrm{K}_{\text {cat }} / \mathrm{K}_{\mathrm{m}}$ obtained for wild-type nisin is in line with previous results in literature, even though a different buffer is used (Lagedroste et al., 2017). The largest differences are noticed in the kinetic parameters of nis-Thrombin and nis-Factor $\mathrm{Xa}$, with a 5-6-fold decrease in the catalytic efficiency (Table 3). Although the cleavage efficiency in these cases is reduced, this can be counteracted using prolonged incubation times or a higher enzyme dose, to yield full cleavage (data not shown). It is not surprising that the very similar thrombin site can be cleaved (AVPR vs. ASPR in the wild-type) although the reduction in the catalytic efficiency points at the favored cleavage with a hydrophilic residue in the $\mathrm{P} 3$ position that can interact with the solvent out of the protease active site (Siezen et al., 1995). The replacement of ASPR with the factor Xa cleavage site IEGR introduces additional changes and a negatively charged residue, but is still rather efficiently cleaved by NisP. The presence of negative residues in position P3 is common in other type I lantibiotics processed by a LanP enzyme such as gallidermin or epidermin. In contrast, the mutant A-4D (van der Meer et al., 1994) is not fully cleaved. The predicted interaction partner in the enzyme is a small hydrophobic pocket and therefore the mutation A-4D could not fit well into this cleft (Siezen et al., 1995). Additionally, a weak hydrogen bond interaction between Ser P3 and NisP was modeled, whereas in EpiP the presence of lysine residues around the catalytic site could favor a stronger interaction with the negative charge in epidermin leader peptide (Siezen et al., 1995). Our results support the idea that a small hydrophobic amino acid in the $\mathrm{P} 4$ position and a polar or charged amino acid in the $\mathrm{P} 3$ position may be important for the correct positioning of the leader peptide into the active site of NisP.

The highly conserved proline in the $\mathrm{P} 2$ position in the leader peptide of type I lantibiotics could play an important role in determining the local structure of the leader peptide and facilitating the access of the protease active site to cleave the mature prelantibiotic. It is also related to production levels and transport (Plat et al., 2017). Our data and the self-cleavage sequences in NisP and several other Pro mutants in the position
P2 (van der Meer et al., 1994; Kuipers et al., 2004; Plat et al., 2011; Xu et al., 2014) clearly shows that proline is not essential for the cleavage (Figure 1B).

The highly conserved arginine in the P1 position establishes a strong ionic interaction with aspartate residues in the model structure of NisP (Siezen et al., 1995). This position shows certain flexibility, although the replacements $\mathrm{R}-1 \mathrm{Q}$, which is present in other type I lantibiotics such as subtilin, Pep5 or epilancin $15 \mathrm{X}$, and the mutation R-1E present in the mutant nisin V8, dramatically reduces the cleavage efficiency (van der Meer et al., 1994 and this work).

\section{Single Alanine Mutations in the (D)FNLD Box Do Not Hamper Cleavage by NisP}

The (D)FNLD box in lantibiotic leader peptides has been shown to be essential for the optimal interaction with the modification enzymes in nisin biosynthesis machinery and other type I lantibiotics (Lubelski et al., 2009; Khusainov et al., 2011, 2013; Plat et al., 2011, 2013; Knerr and van der Donk, 2012; Abts et al., 2013). Previous works reported the impact of various mutations in this region on the modification extent of nisin monitored by mass-spectrometry and activity tests. However, the activity was measured after activation with trypsin (Khusainov et al., 2011, 2013; Plat et al., 2011). We considered this DFNLD motif as a possible recognition sequence also for the protease NisP. This was previously considered in the homology modeling study in view on unaligned fragments of NisP that were considered important for the binding to the substrate prenisin (Siezen et al., 1995). All the single alanine replacements we tested as substrate for NisP could still be cleaved correctly. This suggests that either this is not a recognition site for $\mathrm{NisP}$ or that single alanine mutations are not enough to disrupt the interaction. Similarly, replacements in the region between the FNLD box and the ASPR cleavage sequence of the leader had no great impact on the production of nisin, as was published before (van der Meer et al., 1994).

\section{NisP as a Tool to Release Diverse Lanthionine-Containing Peptides}

The plug-and-play production system for lantibiotics developed in the last years constitutes a robust platform for the production of diverse lanthionine-containing peptides (Rink et al., 2005; Majchrzykiewicz et al., 2010; van Heel et al., 2013, 2016). Moreover, prelantibiotics have no biological activity and higher yields can be achieved (Valsesia et al., 2007). Thus, a leader peptidase with broad specificity for the peptide moiety behind the cleavage site is desired. A cheap peptidase capable of working directly in culture broth is preferred since this can facilitate efforts during high-throughput screening approaches. NisP fulfills these two criteria and constitutes a valuable tool for the cleavage of the leader peptide in the production of lanthionine-stabilized peptide hormones (Kluskens et al., 2009) as well as fully modified non-cognate prelantibiotics (Figure 5). The increased sensitivity compared to the plasmid free strain can be due to stress caused by the production of the protease (data not shown). The attempts to express the lantibiotic protease ElxP in the wild-type producer also caused toxicity issues (Ortega et al., 2014). 
Various proteases are commonly used for the cleavage of recombinant proteins with an affinity tag attached, such as TEV protease, enterokinase, Factor $\mathrm{Xa}$, or thrombin. Some of them cleave at the end of their recognition sequence, whereas some others cleave in between, therefore adding extra residues after the cleavage site (i.e., TEV protease). The latter proteases are disadvantageous for our purposes since they leave some amino acids behind that cannot be removed. Factor Xa can tolerate most amino acids behind the cleavage sequence $\mathrm{I}(\mathrm{D} / \mathrm{E}) \mathrm{GR}$ with the exception of lysine and proline. However it needs very controlled conditions and commonly cleaves incompletely making its biotechnological application costly. Thrombin, although it cleaves in the middle of the recognition sequence, shows some flexibility in the residues behind the cleavage site and tolerates different hydrophobic amino acids.

We tested different proteases and showed that NisP, the endoprotease Glu-C, thrombin and trypsin are able to cleave in culture conditions. Factor Xa could not activate prenisin in these conditions. Trypsin and the endoprotease Glu-C are very unspecific, since they can cleave behind positive or negative residues within the propeptide, respectively. This is a limitation to their applicability in many cases. However, the endoprotease Glu-C could be suitable in specific cases due to the low abundance of negative residues in lantibiotics and the $\mathrm{pH}$ conditions during cleavage can favor the cleavage selectivity for either aspartate or glutamic acid.

\section{CONCLUSIONS}

Taken together, the results presented here suggest that the protease NisP has greater substrate tolerance than previously anticipated. The exact recognition motif in the leader peptide of nisin for the binding of NisP is not yet completely resolved, although our results agree with the predicted ionic interaction between Arg in position P1 and NisP as a requirement for efficient cleavage and confirm that the presence of lanthionine rings is not mandatory for the cleavage. The determination of the structure of NisP and the kinetics of the cleavage reaction of the different mutants could surely shed light on

\section{REFERENCES}

Abts, A., Montalban-Lopez, M., Kuipers, O. P., Smits, S. H., and Schmitt, L. (2013). NisC binds the FxLx motif of the nisin leader peptide. Biochemistry 52, 5387-5395. doi: 10.1021/bi4008116

Arnison, P. G., Bibb, M. J., Bierbaum, G., Bowers, A. A., Bugni, T. S., Bulaj, G., et al. (2013). Ribosomally synthesized and post-translationally modified peptide natural products: overview and recommendations for a universal nomenclature. Nat. Prod. Rep. 30, 108-160. doi: 10.1039/C2NP 20085F

Baumann, T., Nickling, J. H., Bartholomae, M., Buivydas, A., Kuipers, O. P., and Budisa, N. (2017). Prospects of in vivo incorporation of non-canonical amino acids for the chemical diversification of antimicrobial peptides. Front. Microbiol. 8:124. doi: 10.3389/fmicb.2017.00124

Bhunia, A. K., Johnson, M. C., and Ray, D. B. (1987). Direct detection of an antimicrobial peptide of Pediococcus acidilactici in sodium dodecyl the residues more directly involved in the binding to NisP. These insights should help to expand the biotechnological potential of NisP as a general tool for the cleavage of proteins with and without lanthionine residues. Our results also show that among all the proteases tested, NisP is the most suitable and inexpensive candidate for the activation of diverse lantibiotics or thioether-stabilized peptides produced with the nisin leader peptide and the modification machinery of nisin.

\section{AUTHOR CONTRIBUTIONS}

Planned and conceived the experiments: MM-L, AvH, and OK. Performed the experiments: MM-L and JD. Analyzed the experiments: MM-L, JD, AvH, and OK. Drafted the manuscript and contributed to the data interpretation: MM-L, JD, AvH, and OK. All authors read, critically revised and approved the final manuscript.

\section{FUNDING}

MM-L was supported by ALW-NWO project SynMod (project number 855.01.162) and the FP7 project Synpeptide. AvH was supported by NWO-STW programme GenBiotics (project number 10466). JD was supported by the Chinese Scholarship Council.

\section{ACKNOWLEDGMENTS}

We thank Prof. Dr. Gert Moll for kindly providing some of the strains used in this work and Dr. Rick Rink for helpful discussions.

\section{SUPPLEMENTARY MATERIAL}

The Supplementary Material for this article can be found online at: https://www.frontiersin.org/articles/10.3389/fmicb. 2018.00160/full\#supplementary-material

Supplementary Figure 1 | Schematic view of a possible workflow for the biotechnological application of NisP using nisin as an example.

Bosma, T., Kuipers, A., Bulten, E., de Vries, L., Rink, R., and Moll, G. N. (2011). Bacterial display and screening of posttranslationally thioether-stabilized peptides. Appl. Environ. Microbiol. 77, 6794-6801. doi: 10.1128/AEM.05550-11

Corvey, C., Stein, T., Düsterhus, S., Karas, M., and Entian, K.-D. (2003). Activation of subtilin precursors by Bacillus subtilis extracellular serine proteases subtilisin (AprE), WprA, and Vpr. Biochem. Biophys. Res. Commun. 304, 48-54. doi: 10.1016/S0006-291X(03)00529-1

De Ruyter, P. G., Kuipers, O. P., and De Vos, W. M. (1996). Controlled gene expression systems for Lactococcus lactis with the food-grade inducer nisin. Appl. Environ. Microbiol. 62, 3662-3667.

Eichenbaum, Z., Federle, M. J., Marra, D., de Vos, W. M., Kuipers, O. P., Kleerebezem, M., et al. (1998). Use of the lactococcal nisA promoter to regulate gene expression in gram-positive bacteria: comparison of induction level and promoter strength. Appl. Environ. Microbiol. 64, 2763-2769. 
Geissler, S., Götz, F., and Kupke, T. (1996). Serine protease EpiP from Staphylococcus epidermidis catalyzes the processing of the epidermin precursor peptide. J. Bacteriol. 178, 284-288. doi: 10.1128/jb.178.1.284-288.1996

Holo, H., and Nes, I. F. (1995). "Transformation of Lactococcus by electroporation," in Electroporation Protocols for Microorganisms (Springer), 195-199. Available online at: http://link.springer.com/protocol/10.1385/0-89603-310-4:195

Khusainov, R., Heils, R., Lubelski, J., Moll, G. N., and Kuipers, O. P. (2011). Determining sites of interaction between prenisin and its modification enzymes NisB and NisC. Mol. Microbiol. 82, 706-718. doi: 10.1111/j.1365-2958.2011.07846.x

Khusainov, R., and Kuipers, O. P. (2012). When the leader gets loose: in vivo biosynthesis of a leaderless prenisin is stimulated by a transacting leader peptide. Chembiochem. Eur. J. Chem. Biol. 13, 2433-2438. doi: $10.1002 /$ cbic. 201200437

Khusainov, R., and Kuipers, O. P. (2013). The presence of modifiable residues in the core peptide part of precursor nisin is not crucial for precursor nisin interactions with NisB- and NisC. PLoS ONE 8:e74890. doi: 10.1371/journal.pone. 0074890

Khusainov, R., Moll, G. N., and Kuipers, O. P. (2013). Identification of distinct nisin leader peptide regions that determine interactions with the modification enzymes NisB and NisC. FEBS Open Bio. 3, 237-242. doi: 10.1016/j.fob.2013.05.001

Kluskens, L. D., Kuipers, A., Rink, R., de Boef, E., Fekken, S., Driessen, A. J. M., et al. (2005). Post-translational modification of therapeutic peptides by NisB, the dehydratase of the lantibiotic nisin. Biochemistry 44, 12827-12834. doi: $10.1021 /$ bi050805p

Kluskens, L. D., Nelemans, S. A., Rink, R., de Vries, L., Meter-Arkema, A., Wang, Y., et al. (2009). Angiotensin-(1-7) with thioether bridge: an angiotensinconverting enzyme-resistant, potent angiotensin-(1-7) analog. J. Pharmacol. Exp. Ther. 328, 849-854. doi: 10.1124/jpet.108.146431

Knerr, P. J., and van der Donk, W. A. (2012). Discovery, biosynthesis, and engineering of lantipeptides. Annu. Rev. Biochem. 81, 479-505. doi: 10.1146/annurev-biochem-060110-113521

Kuhn, M. L., Prachi, P., Minasov, G., Shuvalova, L., Ruan, J., Dubrovska, I., et al. (2014). Structure and protective efficacy of the Staphylococcus aureus autocleaving protease EpiP. FASEB J. 28, 1780-1793 doi: 10.1096/fj.13241737

Kuipers, A., de Boef, E., Rink, R., Fekken, S., Kluskens, L. D., Driessen, A. J. M., et al. (2004). NisT, the transporter of the lantibiotic nisin, can transport fully modified, dehydrated, and unmodified prenisin and fusions of the leader peptide with non-lantibiotic peptides. J. Biol. Chem. 279, 22176-22182. doi: 10.1074/jbc.M312789200

Kuipers, O. P., Beerthuyzen, M. M., de Ruyter, P. G., Luesink, E. J., and de Vos, W. M. (1995). Autoregulation of nisin biosynthesis in Lactococcus lactis by signal transduction. J. Biol. Chem. 270, 27299-27304. doi: 10.1074/jbc.270.45.27299

Kuipers, O. P., Beerthuyzen, M. M., Siezen, R. J., and De Vos, W. M. (1993). Characterization of the nisin gene cluster nisABTCIPR of Lactococcus lactis. Requirement of expression of the nisA and nisI genes for development of immunity. Eur. J. Biochem. FEBS 216, 281-291. doi: 10.1111/j.1432-1033.1993.tb18143.x

Kuipers, O. P., de Ruyter, P. G., Kleerebezem, M., and de Vos, W. M. (1997). Controlled overproduction of proteins by lactic acid bacteria. Trends Biotechnol. 15, 135-140. doi: 10.1016/S0167-7799(97)01029-9

Laemmli, U. K. (1970). Cleavage of structural proteins during the assembly of the head of bacteriophage T4. Nature 227, 680-685. doi: 10.1038/227680a0

Lagedroste, M., Smits, S. H. J., and Schmitt, L. (2017). Substrate specificity of the secreted nisin leader peptidase NisP. Biochem. Mosc. 56, 4005-4014. doi: 10.1021/acs.biochem.7b00524

Lineweaver, H., and Burk, D. (1934). The determination of enzyme dissociation constants. J. Am. Chem. Soc. 56, 658-666. doi: 10.1021/ja01318a036

Lubelski, J., Khusainov, R., and Kuipers, O. P. (2009). Directionality and coordination of dehydration and ring formation during biosynthesis of the lantibiotic nisin. J. Biol. Chem. 284, 25962-25972. doi: 10.1074/jbc.M109.026690

Lubelski, J., Rink, R., Khusainov, R., Moll, G. N., and Kuipers, O. P. (2008). Biosynthesis, immunity, regulation, mode of action and engineering of the model lantibiotic nisin. Cell. Mol. Life Sci. CMLS 65, 455-476. doi: 10.1007/s00018-007-7171-2
Majchrzykiewicz, J. A., Lubelski, J., Moll, G. N., Kuipers, A., Bijlsma, J. J. E., Kuipers, O. P., et al. (2010). Production of a class II two-component lantibiotic of Streptococcus pneumoniae using the class I nisin synthetic machinery and leader sequence. Antimicrob. Agents Chemother. 54, 1498-1505. doi: 10.1128/AAC.00883-09

Meyer, C., Bierbaum, G., Heidrich, C., Reis, M., Süling, J., Iglesias-Wind, M. I., et al. (1995). Nucleotide sequence of the lantibiotic Pep5 biosynthetic gene cluster and functional analysis of PepP and PepC. Evidence for a role of PepC in thioether formation. Eur. J. Biochem. FEBS 232, 478-489. doi: 10.1111/j.1432-1033.1995.tb20834.x

Mierau, I., and Kleerebezem, M. (2005). 10 years of the nisin-controlled gene expression system (NICE) in Lactococcus lactis. Appl. Microbiol. Biotechnol. 68, 705-717. doi: 10.1007/s00253-005-0107-6

Moll, G. N., Kuipers, A., and Rink, R. (2010). Microbial engineering of dehydroamino acids and lanthionines in non-lantibiotic peptides. Antonie Van Leeuwenhoek 97, 319-333. doi: 10.1007/s10482-010-9418-4

Montalbán-López, M., van Heel, A. J., and Kuipers, O. P. (2017). Employing the promiscuity of lantibiotic biosynthetic machineries to produce novel antimicrobials. FEMS Microbiol. Rev. 41, 5-18. doi: 10.1093/femsre/fuw034

Montalbán-López, M., Zhou, L., Buivydas, A., van Heel, A. J., and Kuipers, O. P. (2012). Increasing the success rate of lantibiotic drug discovery by Synthetic Biology. Exp. Opin. Drug Discov. 7, 695-709. doi: 10.1517/17460441.2012.693476

Mota-Meira, M., LaPointe, G., Lacroix, C., and Lavoie, M. C. (2000). MICs of mutacin B-Ny266, nisin A, vancomycin, and oxacillin against bacterial pathogens. Antimicrob. Agents Chemother. 44, 24-29. doi: 10.1128/AAC.44.1.24-29.2000

Mu, D., Montalbán-López, M., Deng, J., and Kuipers, O. P. (2015). Lantibiotic reductase LtnJ substrate selectivity assessed with a collection of nisin derivatives as substrates. Appl. Environ. Microbiol. 81, 3679-3687. doi: 10.1128/AEM.00475-15

Oman, T. J., and van der Donk, W. A. (2010). Follow the leader: the use of leader peptides to guide natural product biosynthesis. Nat. Chem. Biol. 6, 9-18. doi: $10.1038 /$ nchembio. 286

Ortega, M. A., Velásquez, J. E., Garg, N., Zhang, Q., Joyce, R. E., Nair, S. K., et al. (2014). Substrate specificity of the lanthipeptide peptidase ElxP and the oxidoreductase ElxO. ACS Chem. Biol. 9, 1718-1725. doi: 10.1021/cb5002526

Piper, C., Draper, L. A., Cotter, P. D., Ross, R. P., and Hill, C. (2009). A comparison of the activities of lacticin 3147 and nisin against drug-resistant Staphylococcus aureus and Enterococcus species. J. Antimicrob. Chemother. 64, 546-551. doi: 10.1093/jac/dkp221

Plat, A., Kluskens, L. D., Kuipers, A., Rink, R., and Moll, G. N. (2011). Requirements of the engineered leader peptide of nisin for inducing modification, export, and cleavage. Appl. Environ. Microbiol. 77, 604-611. doi: 10.1128/AEM.01503-10

Plat, A., Kuipers, A., Crabb, J., Rink, R., and Moll, G. N. (2017). Mutagenesis of nisin's leader peptide proline strongly modulates export of precursor nisin. Antonie Van Leeuwenhoek 110, 321-330. doi: 10.1007/s10482-0160802-6

Plat, A., Kuipers, A., Rink, R., and Moll, G. N. (2013). Mechanistic aspects of lanthipeptide leaders. Curr. Protein Pept. Sci. 14, 85-96. doi: $10.2174 / 1389203711314020001$

Rink, R., Kluskens, L. D., Kuipers, A., Driessen, A. J. M., Kuipers, O. P., and Moll, G. N. (2007a). NisC, the cyclase of the lantibiotic nisin, can catalyze cyclization of designed nonlantibiotic peptides. Biochemistry Mosc. 46, 13179-13189. doi: 10.1021/bi700106z

Rink, R., Kuipers, A., de Boef, E., Leenhouts, K. J., Driessen, A. J. M., Moll, G. N., et al. (2005). Lantibiotic structures as guidelines for the design of peptides that can be modified by lantibiotic enzymes. Biochemistry Mosc. 44, 8873-8882. doi: $10.1021 /$ bi050081h

Rink, R., Wierenga, J., Kuipers, A., Kluskens, L. D., Driessen, A. J. M., Kuipers, O. P., et al. (2007b). Dissection and modulation of the four distinct activities of nisin by mutagenesis of rings $\mathrm{A}$ and $\mathrm{B}$ and by $\mathrm{C}$-terminal truncation. Appl. Environ. Microbiol. 73, 5809-5816. doi: 10.1128/AEM.01104-07

Sambrook, J., and Russell, D. W. (2001). Molecular Cloning: A Laboratory Manual, $3 r d$ Edn. Cold Spring Harbor, NY: Cold Spring Harbor Laboratory Press.

Siezen, R. J., Rollema, H. S., Kuipers, O. P., and de Vos, W. M. (1995). Homology modelling of the Lactococcus lactis leader peptidase NisP and its 
interaction with the precursor of the lantibiotic nisin. Protein Eng. 8, 117-125. doi: $10.1093 /$ protein/8.2.117

Simon, D., and Chopin, A. (1988). Construction of a vector plasmid family and its use for molecular cloning in Streptococcus lactis. Biochimie 70, 559-566. doi: 10.1016/0300-9084(88)90093-4

Valsesia, G., Medaglia, G., Held, M., Minas, W., and Panke, S. (2007). Circumventing the effect of product toxicity: development of a novel two-stage production process for the lantibiotic gallidermin. Appl. Environ. Microbiol. 73, 1635-1645. doi: 10.1128/AEM.01969-06

van der Meer, J. R., Polman, J., Beerthuyzen, M. M., Siezen, R. J., Kuipers, O. P., and De Vos, W. M. (1993). Characterization of the Lactococcus lactis nisin A operon genes nis $P$, encoding a subtilisin-like serine protease involved in precursor processing, and nisR, encoding a regulatory protein involved in nisin biosynthesis. J. Bacteriol. 175, 2578-2588. doi: 10.1128/jb.175.9.2578-2588.1993

van der Meer, J. R., Rollema, H. S., Siezen, R. J., Beerthuyzen, M. M., Kuipers, O. P., and de Vos, W. M. (1994). Influence of amino acid substitutions in the nisin leader peptide on biosynthesis and secretion of nisin by Lactococcus lactis. J. Biol. Chem. 269, 3555-3562.

van Heel, A. J., Kloosterman, T. G., Montalban-Lopez, M., Deng, J., Plat, A., Baudu, B., et al. (2016). Discovery, production and modification of five novel lantibiotics using the promiscuous nisin modification machinery. ACS Synth. Biol. 5, 1146-1154. doi: 10.1021/acssynbio.6b00033

van Heel, A. J., Mu, D., Montalbán-López, M., Hendriks, D., and Kuipers, O. P. (2013). Designing and producing modified, new-to-nature peptides with antimicrobial activity by use of a combination of various lantibiotic modification enzymes. ACS Synth. Biol. 2, 397-404. doi: 10.1021/sb3001084

Velásquez, J. E., Zhang, X., and van der Donk, W. A. (2011). Biosynthesis of the antimicrobial peptide epilancin 15X and its N-terminal lactate. Chem. Biol. 18, 857-867. doi: 10.1016/j.chembiol.2011.05.007
Völler, G. H., Krawczyk, B., Ensle, P., and Süssmuth, R. D. (2013). Involvement and unusual substrate specificity of a prolyl oligopeptidase in class III lanthipeptide maturation. J. Am. Chem. Soc. 135, 7426-7429. doi: 10.1021/ja402296m

Xu, Y., Li, X., Li, R., Li, S., Ni, H., Wang, H., et al. (2014). Structure of the nisin leader peptidase NisP revealing a C-terminal autocleavage activity. Acta Crystallogr. D Biol. Crystallogr. 70, 1499-1505. doi: $10.1107 /$ S1399004714004234

Yang, X., and van der Donk, W. A. (2013). Ribosomally synthesized and posttranslationally modified peptide natural products: new insights into the role of leader and core peptides during biosynthesis. Chem. Weinh. Bergstr. Ger. 19, 7662-7677. doi: 10.1002/chem.201300401

Zambaldo, C., Luo, X., Mehta, A. P., and Schultz, P. G. (2017). Recombinant macrocyclic lanthipeptides incorporating non-canonical amino acids. J. Am. Chem. Soc. 139, 11646-11649. doi: 10.1021/jacs.7b04159

Zhou, L., Shao, J., Li, Q., van Heel, A. J., de Vries, M. P., Broos, J., et al. (2016). Incorporation of tryptophan analogues into the lantibiotic nisin. Amino Acids 48, 1309-1318. doi: 10.1007/s00726-016-2186-3

Conflict of Interest Statement: The authors declare that the research was conducted in the absence of any commercial or financial relationships that could be construed as a potential conflict of interest.

Copyright (๑) 2018 Montalbán-López, Deng, van Heel and Kuipers. This is an openaccess article distributed under the terms of the Creative Commons Attribution License (CC BY). The use, distribution or reproduction in other forums is permitted, provided the original author(s) and the copyright owner are credited and that the original publication in this journal is cited, in accordance with accepted academic practice. No use, distribution or reproduction is permitted which does not comply with these terms. 